\title{
Correlation between Vitamin D Deficiency and Seborrheic Dermatitis in Patients Referred to the Dermatology Clinic of Sina Hospital, Hamadan, Iran
}

\author{
Mohammadreza Sobhan 1,* (iD , Elham Khanlarzadeh², Mahrokh Moradi Rozbhani \\ ${ }^{I}$ Assistant Professor, Department of Dermatology, School of Medicine, Psoriasis Research Center, Hamadan University of \\ Medical Sciences, Hamadan, Iran \\ ${ }^{2}$ Assistant Professor, Department of Community Medicine, School of Medicine, Hamadan University of Medical Sciences, \\ Hamedan, Iran \\ ${ }^{3}$ General Practitioner, Hamadan University of Medical Sciences, Hamadan, Iran \\ * Corresponding Author: Mohammadreza Sobhan, Department of Dermatology, School of Medicine, Psoriasis Research \\ Center, Hamadan University of Medical Sciences, Hamadan,Iran.Email: mreza_sobhan@yahoo.com
}

\begin{tabular}{|c|c|}
\hline & Abstract \\
\hline $\begin{array}{l}\text { Received: } 27.12 .2020 \\
\text { Accepted: } 13.04 .2021\end{array}$ & \multirow{3}{*}{$\begin{array}{l}\text { Background and Objective: Seborrheic dermatitis is one of the mos } \\
\text { common inflammatory skin diseases that affect the sebaceous glands } \\
\text { Although the exact role of vitamin D in this disease is still not clearly } \\
\text { understood, some studies have shown lower serum levels of vitamin D in } \\
\text { seborrheic dermatitis patients. This study aimed to investigate the correlation } \\
\text { between vitamin D deficiency and seborrheic dermatitis. } \\
\text { Materials and Methods: This cross-sectional case-control study was } \\
\text { conducted in Sina Hospital, Hamadan, Iran. The study sample included } 39 \\
\text { seborrheic dermatitis patients (case group) and } 39 \text { healthy individuals } \\
\text { (control group) who were matched in terms of gender and age. The groups } \\
\text { were then compared regarding serum vitamin D level. Statistical analysi } \\
\text { was performed in SPSS software (version } 16.0 \text {; SPSS Inc.Chicago, IL). } \\
\text { Results: There were no significant differences between the two groups in } \\
\text { terms of age, gender, educational level, place of residence, and occupationa } \\
\text { status. The mean serum levels of vitamin D in the case and control groups } \\
\text { were } 11.82 \pm 5.56 \text { and } 21.38 \pm 6.79 n g / m l, \text { respectively (P=0.001). Furthermore } \\
\text { in the case and control groups, } 18 \text { ( } 46.2 \%) \text { and } 1 \text { ( } 2.6 \%) \text { individuals had } \\
\text { vitamin D deficiency; } 20 \text { (51.3\%) and } 34 \text { ( } 87.2 \%) \text { cases had inadequate } \\
\text { vitamin D levels; and } 1(2.6 \%) \text { and } 4 \text { (10.3\%) subjects had adequate levels of } \\
\text { vitamin D, respectively. Therefore, the serum level of vitamin D was } \\
\text { significantly lower in the case group, compared to the control group } \\
\text { (P=0.001). Moreover, the serum level of vitamin D did not correlate with the } \\
\text { duration and severity of seborrheic dermatitis disease (P>0.05). } \\
\text { Conclusion: According to the findings of this study, patients with } \\
\text { seborrheic dermatitis had lower serum vitamin D levels, compared to the } \\
\text { general population, which may be related to the pathogenicity of the disease } \\
\text { Keywords: Seborrheic Dermatitis, Severity of Disease, Vitamin D }\end{array}$} \\
\hline $\begin{array}{l}\text { How to Cite this Article: } \\
\text { Sobhan M, Khanlarzadeh E, } \\
\text { Moradi Rozbhani M. Correlation } \\
\text { between Vitamin D Deficiency } \\
\text { and Seborrheic Dermatitis in } \\
\text { Patients Referred to the } \\
\text { Dermatology Clinic of Sina } \\
\text { Hospital, Hamadan, Iran. } \\
\text { Avicenna J Clin Med. 2021; } \\
\text { 28(1): 20-27. DOI: 10.52547/ } \\
\text { ajcm.28.1.20 }\end{array}$ & \\
\hline & \\
\hline
\end{tabular}

Copyright $\odot 2021$ The Author(s); Published by Hamadan University of Medical Sciences. This is an open-access article distributed under the terms of the Creative Commons Attribution License (http://creativecommons.org/licenses/by-nc/4.0/), which permits unrestricted use, distribution, and reproduction in any medium, provided the original work is properly cited. 
do: $10.52547 /$ ajcm.28.1.20

\title{
بررسى همراهى كمبود ويتامين D و درماتيت سبورئيك در مراجعه كنندكان به درمانكاه و بخش يوست بيمارستان سيناى همدان
}

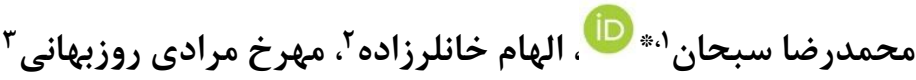

' استاديار، گروه بيمارىهاى يوست، دانشكده يزشكى، مركز تحقيقات يسوريازيس، دانشگاه علوم يزشكى همدان، همدان، ايران

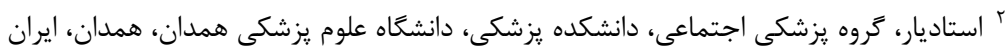

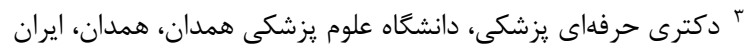

* نويسنده مسئول: محمدرضا سبحان، گروه يوست، دانشكده يزشكى، مركز تحقيقات يسوريازيس، دانشكاه علوم يزشكى همدان، همدان، ايران. ايميل: mreza_sobhan@yahoo.com

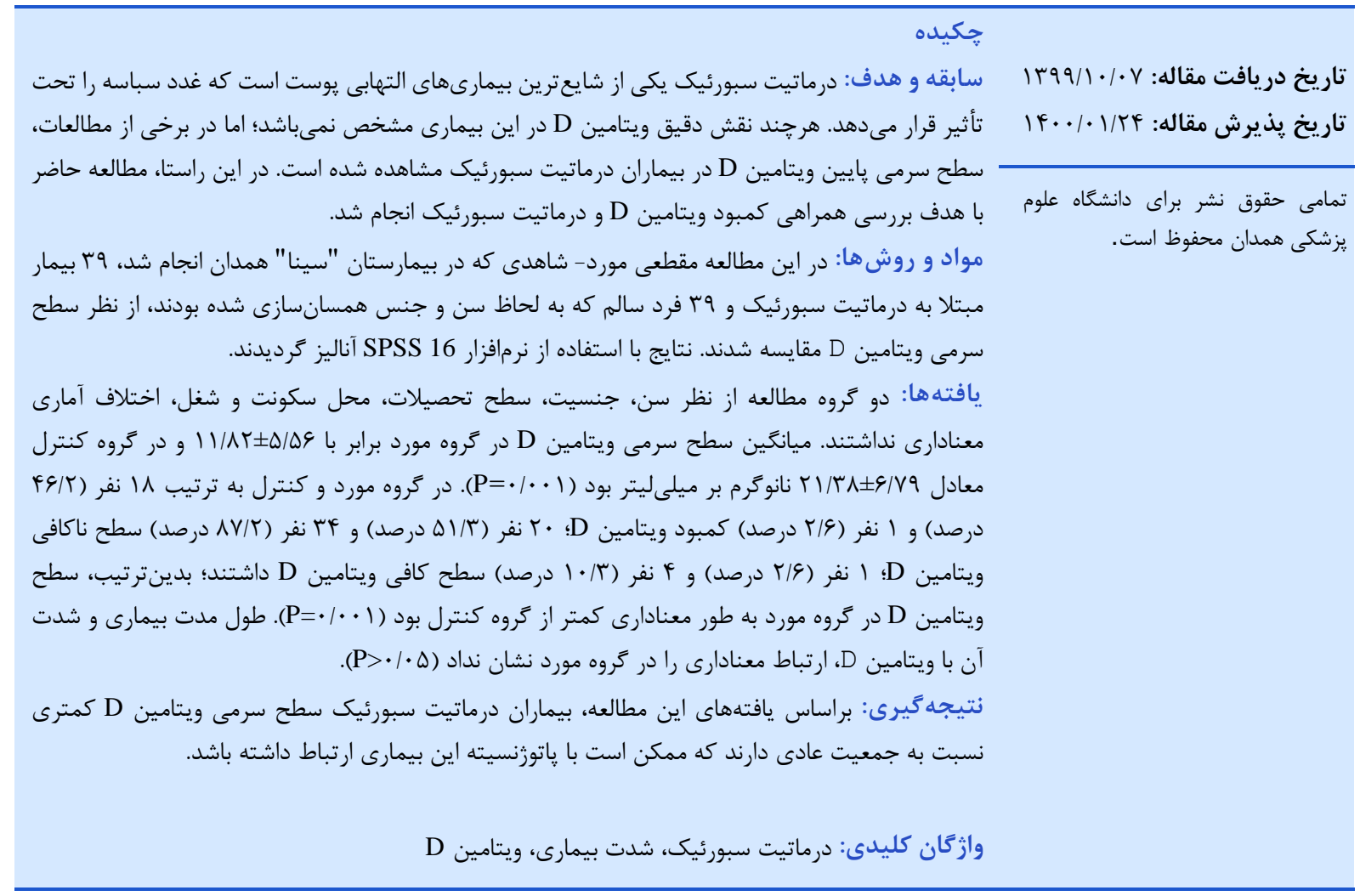

اختلالات نورولوزيك و نقص ايمنى دارند، شديدتر است. اين

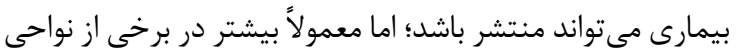

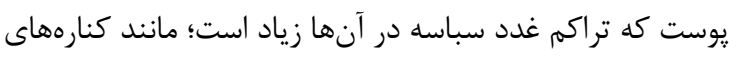

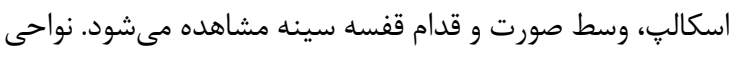

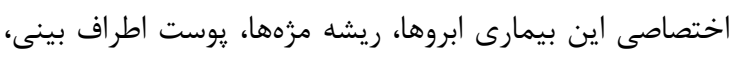

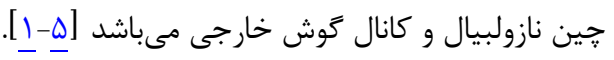
درماتيت سبورئيك يك بيمارى شايع يوستى مولتىفاكتوريال

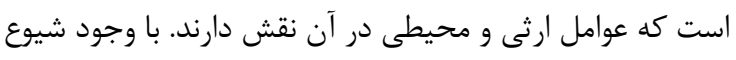

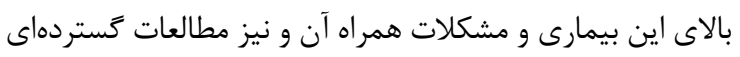

درماتيت سبورئيك يك بيمارى التهابى مزمن و عودكننده

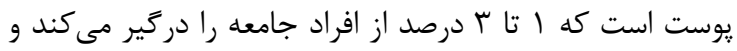

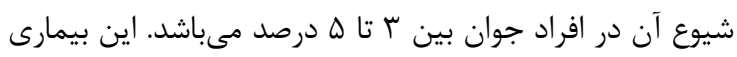

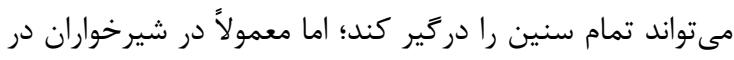

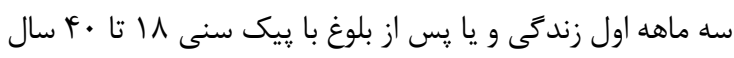

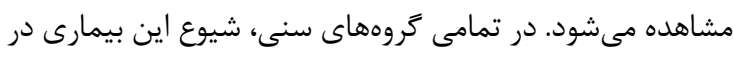

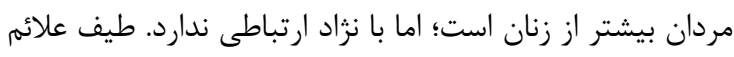

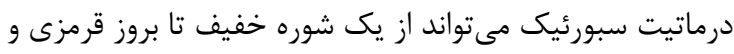
يوستهريزى شديد متفاوت باشد. اين بيمارى در بيمارانى كه 
معدنى استخوان) و ميوياتى يروكزيمال مىشود [ع] [1]. علاوهبراين،

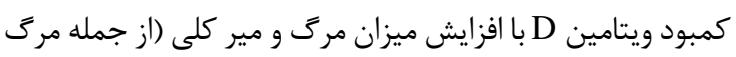

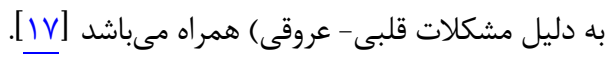

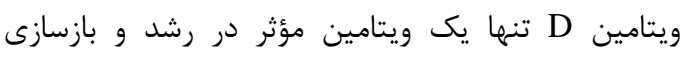

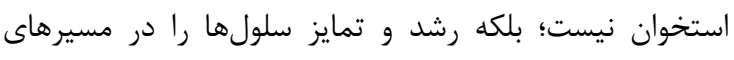

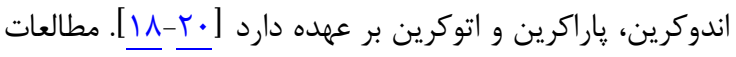

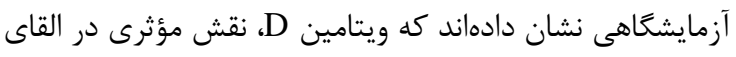

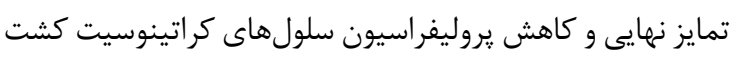

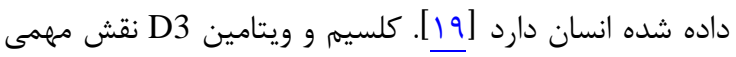

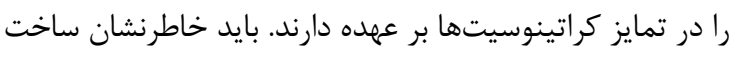

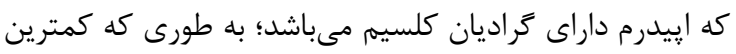

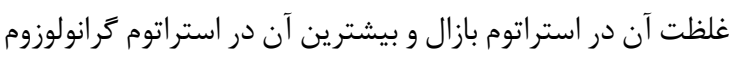

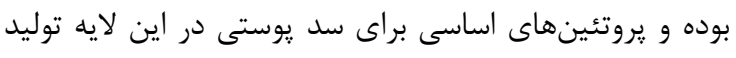

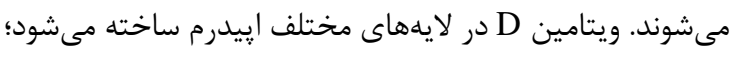

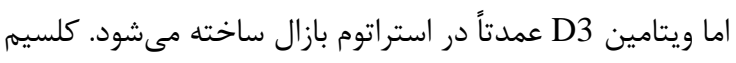

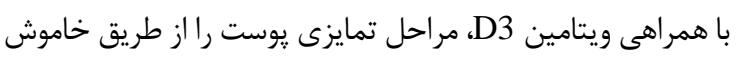

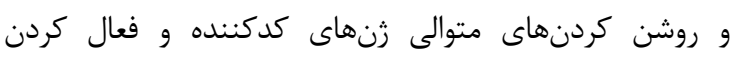

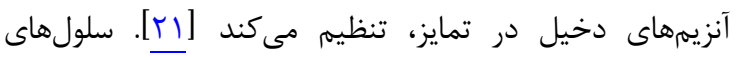

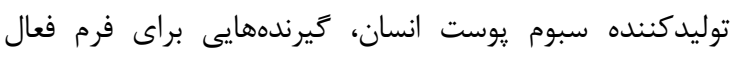

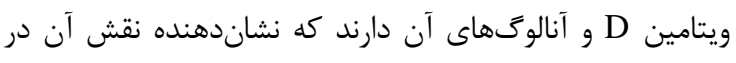

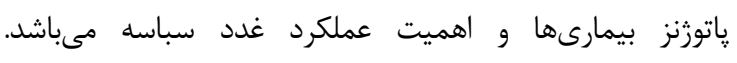

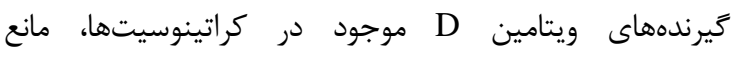

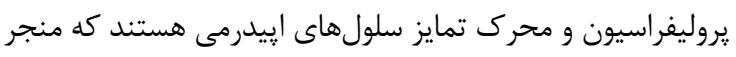

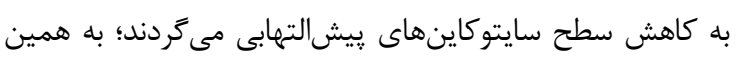

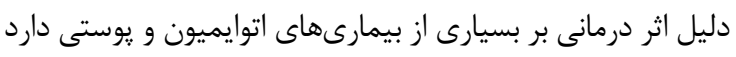

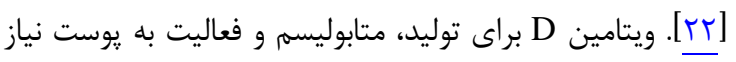

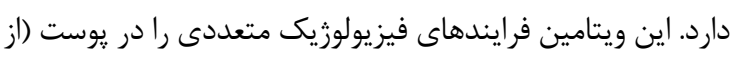

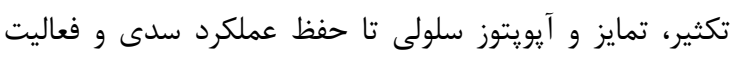

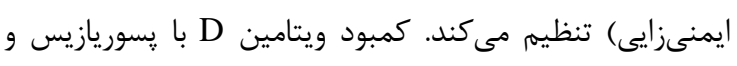

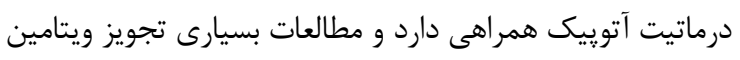

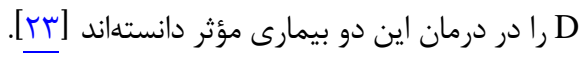

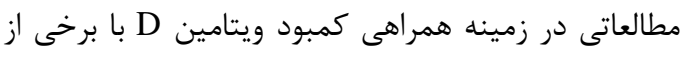

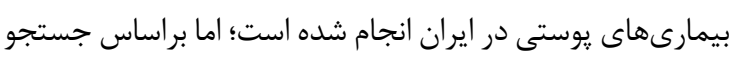

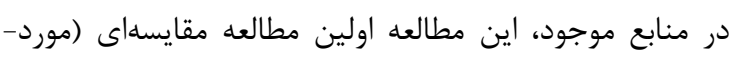
شاهدى) كشورى با هدف تعيين سطح ويتامين D در مر بيماران درماتيت سبورئيك مى كباشد.

\section{مواد و روشها}

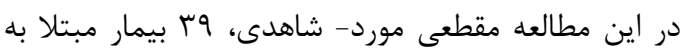

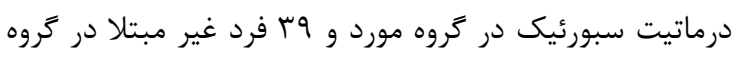

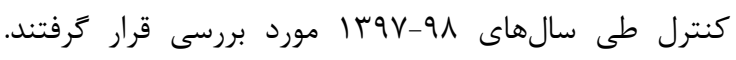

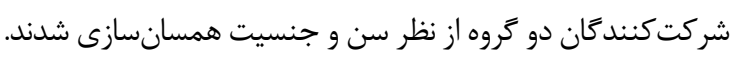

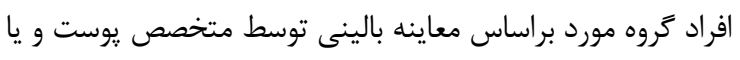
بررسىهاى آسيبشناسى به عنوان بيمار دراني ترماتيت سبورئيك
كه در اين زمينه صورت كرفته است، هنوز ياتورنسيته آن به طور

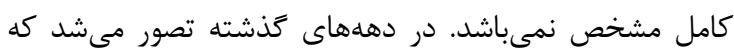

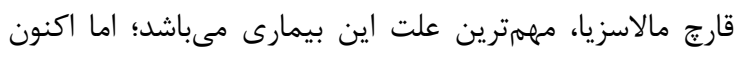

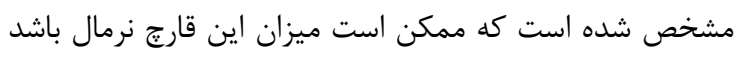

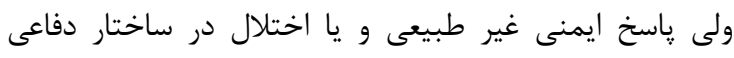

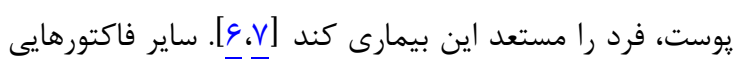

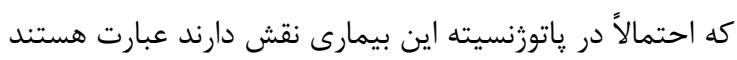

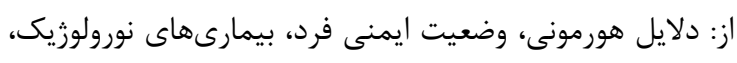

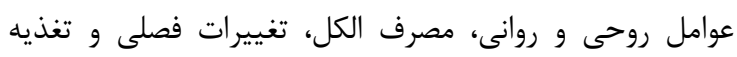

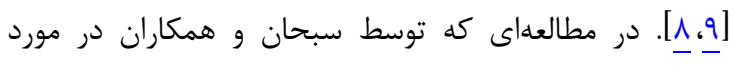

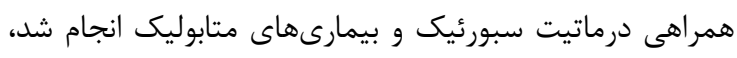

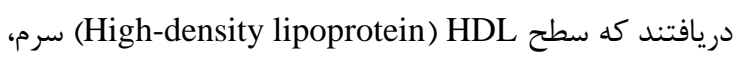
فشار خون سيستوليك و اندازه دور كمر با بيمارى درماتيت إندانيت

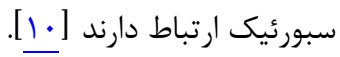
ويتامين D تنها ويتامينى است كه توسط يوست بدن وارن و در در

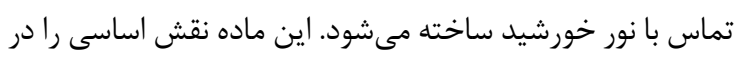

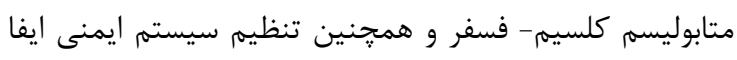

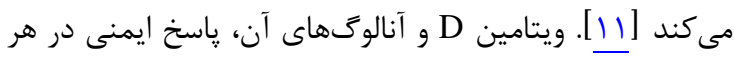

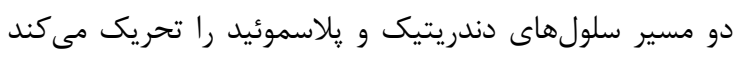

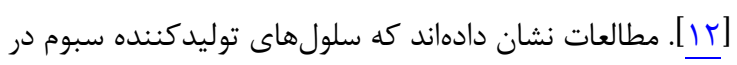

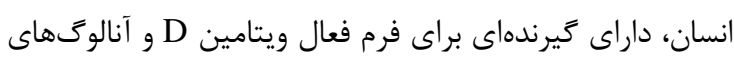

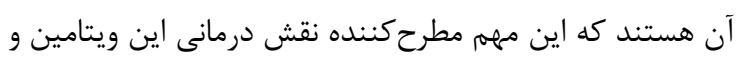

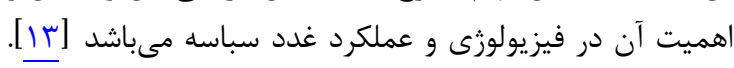

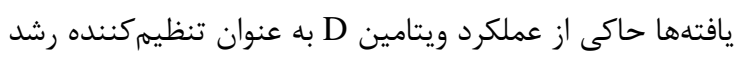

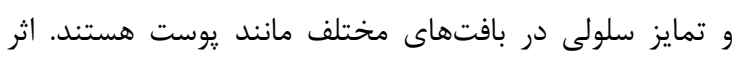
ويتامين D بر مهار تكثير و تحريك تمايز كراتينوسيتها،

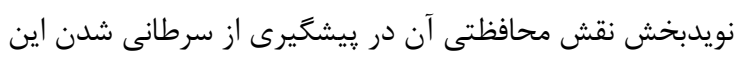

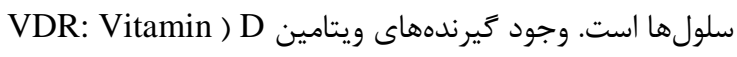
(D Receptor

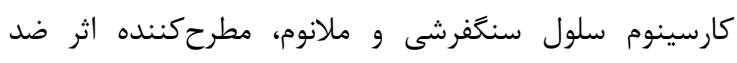

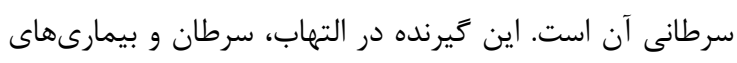

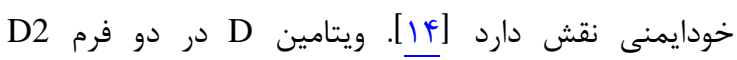
وجود دارد. عمده (cholecalciferol) D3 و ورم (ergocalciferol) ويتامين D3 به وسيله اشعه فرابنفش خورشيد از مولكول

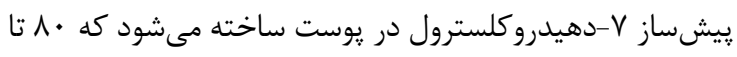

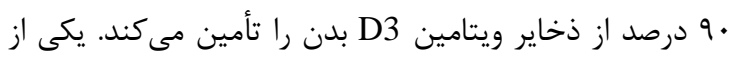

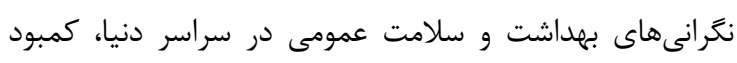

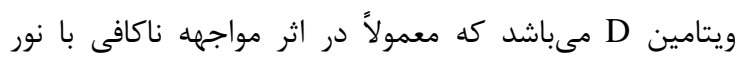

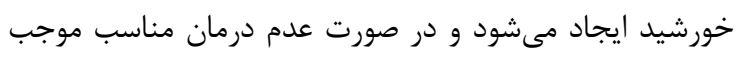

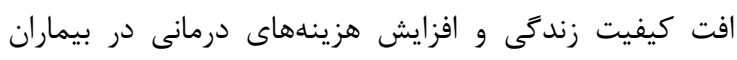

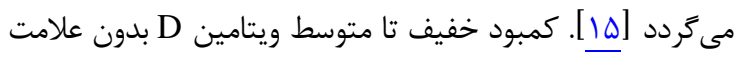

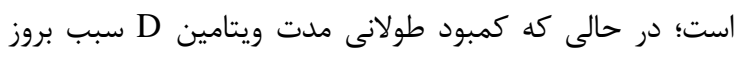

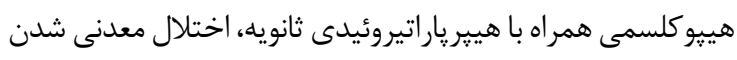

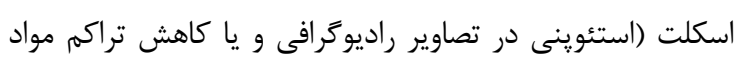


شدت بيمارى) در دو كروه از آزمون مربع كاى بجره كرفته شد. از

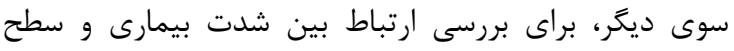

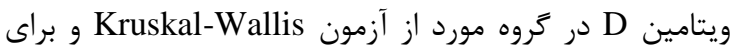

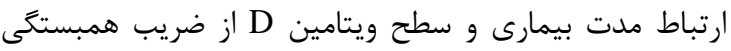
Spearman

\section{بافته ها}

در اين مطالعه 9" فرد مبتلا به درماتيت سبورئيك و و جس فرد

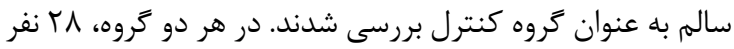

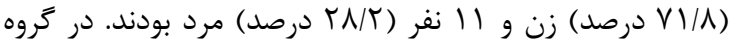

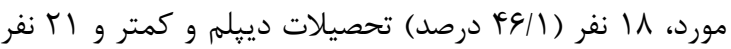

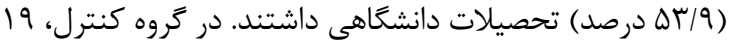

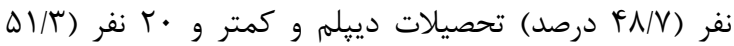

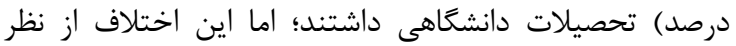

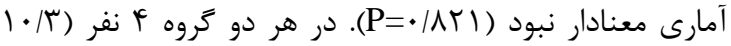

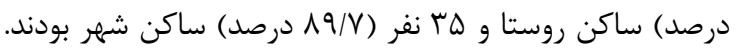

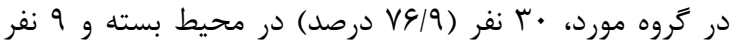

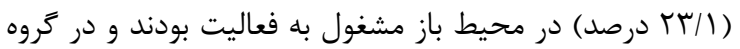

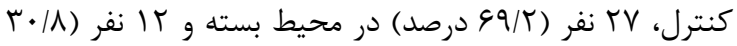

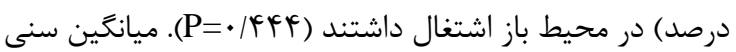

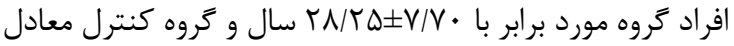


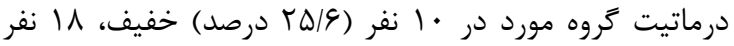

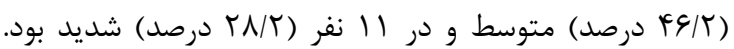
شايان ذكر است موردى از بيمارى سبورئيك درماتيت بسيار

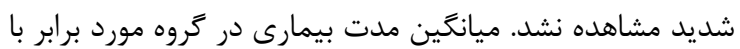

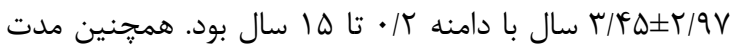

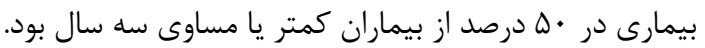

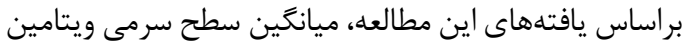

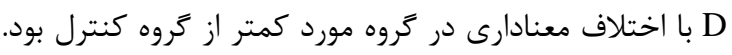

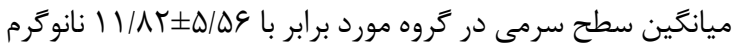
بر ميلىليتر و در كروه كنترل معادل

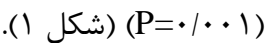

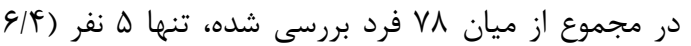

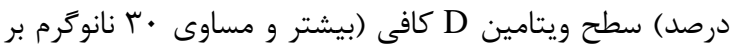

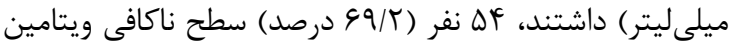

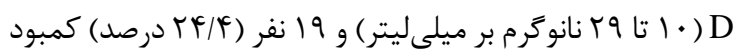

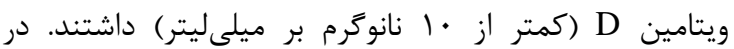

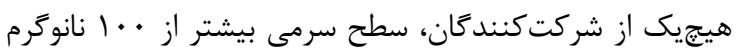

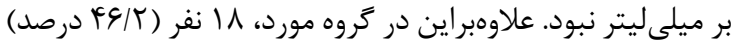

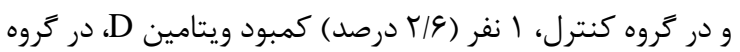

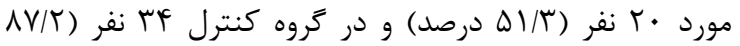

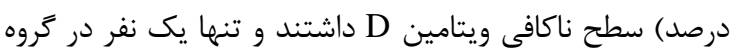

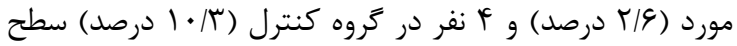

تشخيص داده شده بودند. افراد كروه كنترل، افراد سالم و همراهان

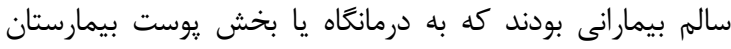

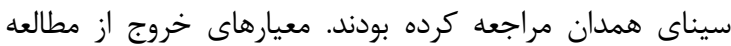

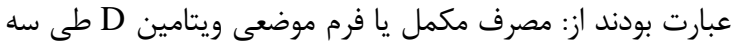

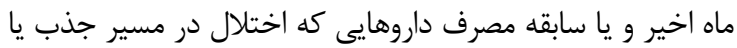
متابوليسم ويتامين D به فرم فعال آن را ايجاد مى كنند؛ به به عنوان مثال كلشى سين، ضد تشنجها، كلوكوكورتيكوئيدها، ضد قارتها

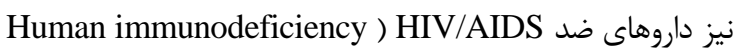
.virus/Acquired immunodeficiency syndrome ابتدا جزئيات و اهداف طرح براى بيماران توضيح داده شد.

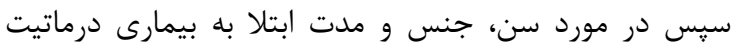

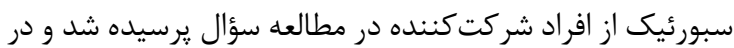

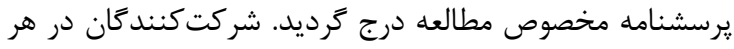

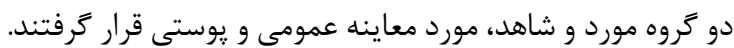

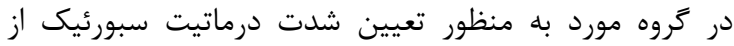
SEDASI: SEborrheic Dermatitis )

ا (Area and Severity Index براساس جهار معيار شامل: وسعت در كيرى، الكوى تظاهر، درجه

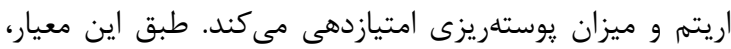

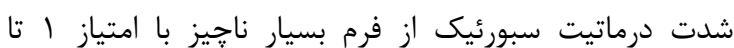

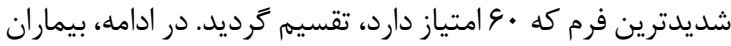

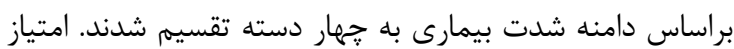

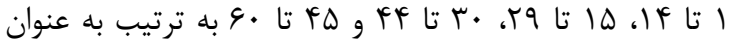
شدت بيمارى خفيف (mild)، متوسط (moderate)، شديد

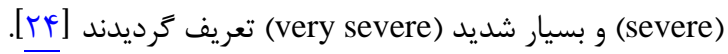

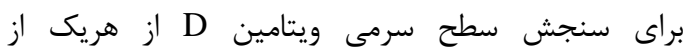

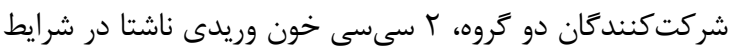

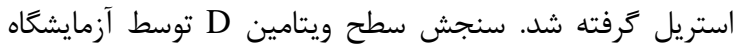

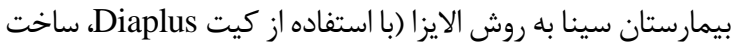

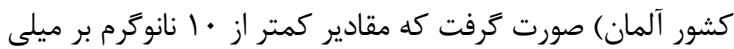

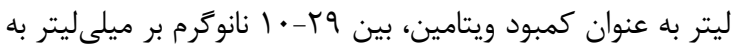

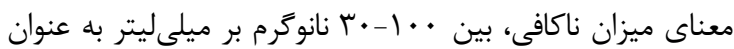

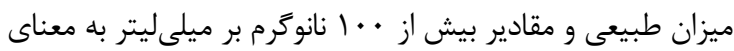

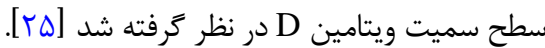

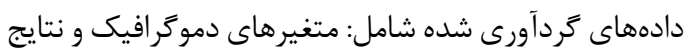
آزمايشات انجام شده در جكليست (data sheet) محققساخته

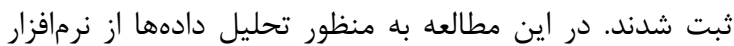
SPS 16 درصد در نظر كرفته شد. توصيف دادهها با استفاده از آمار آنار آنارئ

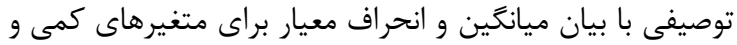
نسبت و درصد براى متغيرهاى كيفى انجام شد. بران براى مرئ مقايسه

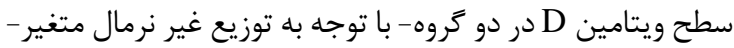

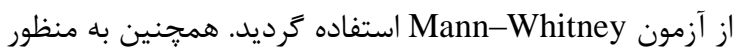
مقايسه متغيرهاى كيفى (كمبود- ناكافى بودن ويتامين D و 

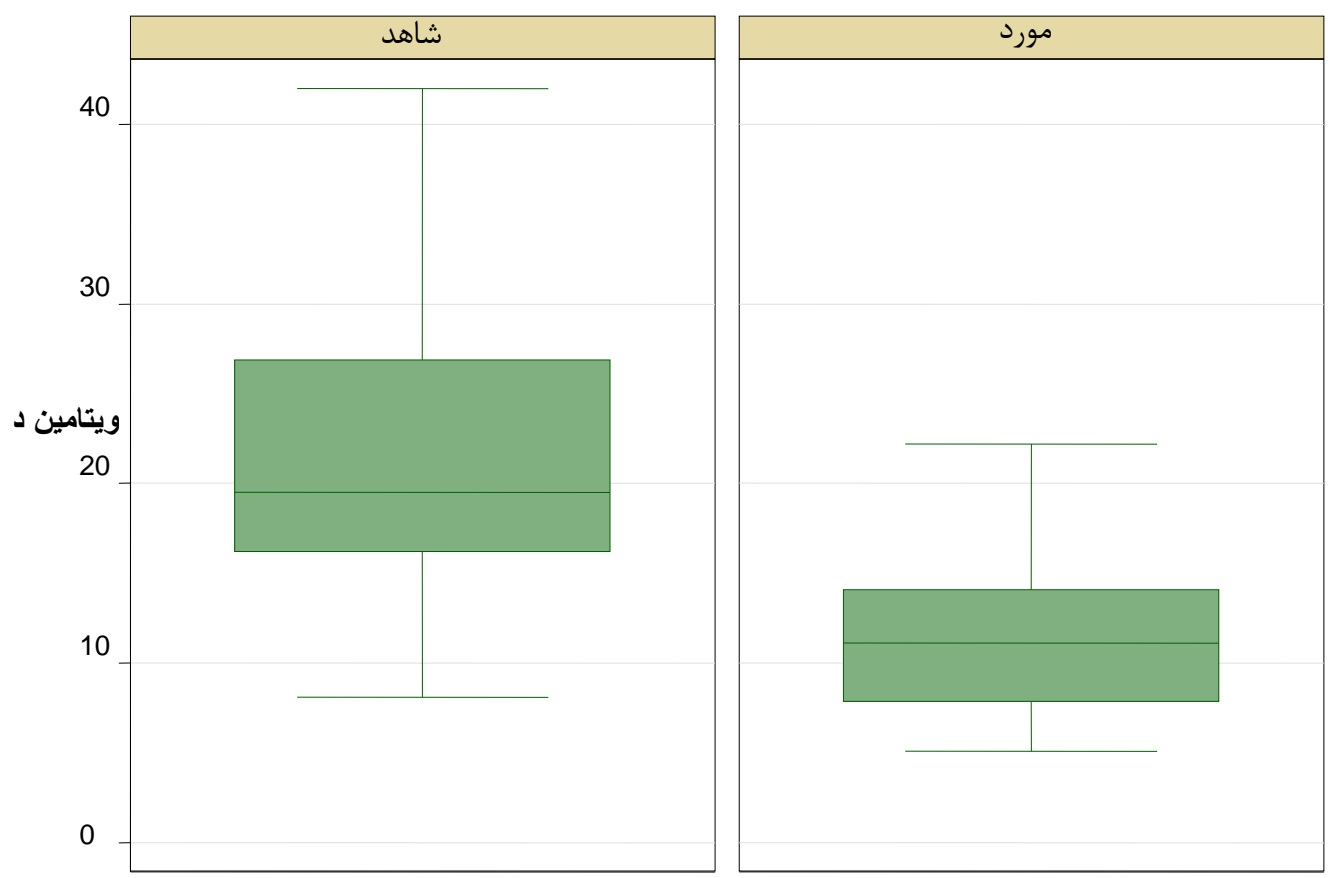

شكل (: نمودار plot box مقايسه سطح سرمى ويتامين D در دو كروه مطالعه (نانوكرم بر ميلىليتر)

جدول ا: مقايسه ميانكين ويتامين D در دو كروه مورد مطالعه براساس جنسيت و كروه سنى

\begin{tabular}{|c|c|c|c|c|c|}
\hline سطح معنادارى & 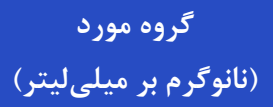 & 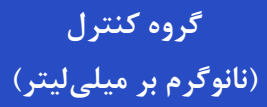 & (نفر) & & \multirow{3}{*}{ جنسيت } \\
\hline$\cdot 1 \cdot \cdot 1$ & $11 / 1 \vee \pm \Delta / 1 \vee$ & 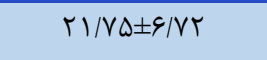 & $\Delta \varphi$ & زن & \\
\hline.$/ \cdot r V$ & $\mid r / \& q \pm q / 4$. & $r \cdot / \mathcal{E T} \pm V / T r$ & Tt & مرد & \\
\hline$\cdot / \cdot \cdot 1$ & $1 \cdot / 9 \pm r / 9$ & $r \cdot / r \pm V / l$ & $\Delta F$ & 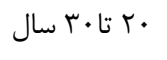 & 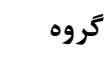 \\
\hline.$/ \cdot 1$ & $1 \% / 9 \pm V / q$ & $T r / V \pm \Delta / G$ & Tr & اس تا•ع سال & سنى \\
\hline
\end{tabular}

براساس نتايج اين مطالعه، بين شدت بيمارى و سطح سرمى

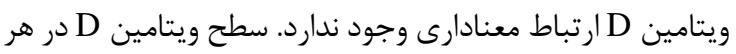

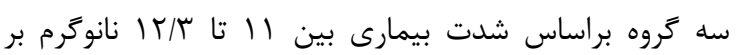

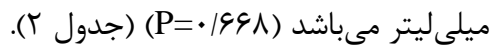
جدول r: ميانگين سطح سرمى ويتامين D در گروه مورد براساس

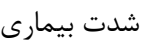

\begin{tabular}{|c|c|c|c|}
\hline معنادارى سطح & انحراف & $\begin{array}{c}\text { ميانكين (نانوكرم ميلىليتر) } \\
\text { ميلى }\end{array}$ & \\
\hline \multirow{3}{*}{.1991} & $r / \cdot \varphi$ & $11 / \mathrm{r}$ & خفيف \\
\hline & $\varepsilon / \Gamma$. & $\mid r / T \wedge$ & متوسط \\
\hline & $\varepsilon / \Gamma \wedge$ & $11 / 4 \wedge$ & شديد \\
\hline
\end{tabular}

درماتيت سبورئيك يك بيمارى شايع و عودكننده است كه

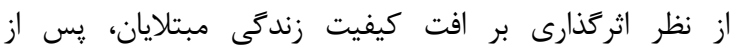

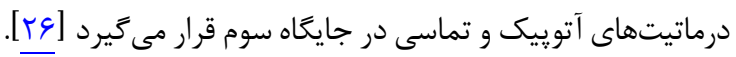
اين بيمارى در سراسر جهان و در تمام قوميتها مشاهده مى دئود
ويتامين D كافى داشتند ( ( P= P= P). براساس گروهبندى سنى و

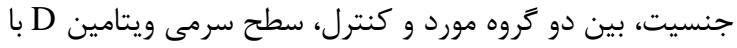
اختلاف معنادارى در كروه كنترل بيشتر از مورد بود (جدول لين ().

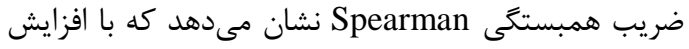
مدت بيمارى، سطح ويتامين D در گروه مورد كاهش مي ئيسابد؛ اما

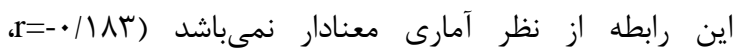

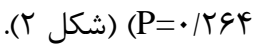

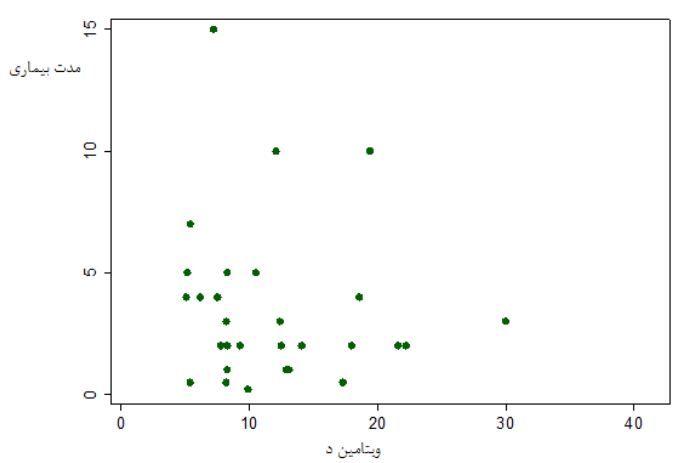

شكل r: نمودار يراكنش (scatter) ارتباط بين طول مدت بيمارى (سال) و سطح ويتامين D (نانو مرم بر ميلى ليتر ) 
هفته، سطح ويتامين D بالاتر يا مساوى · † نانوگرم بر ميلىليتر داشتند (بدون توجه به آنكه مكمل ويتامين يا دارونما دريافت

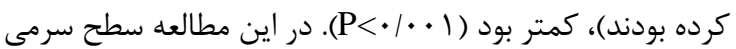

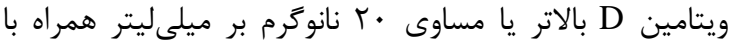

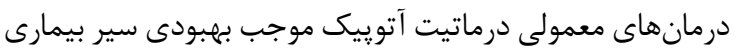

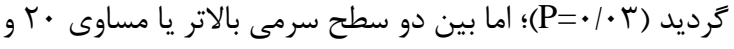

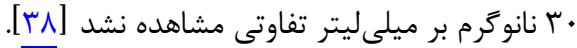

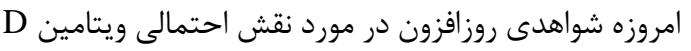

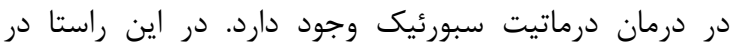

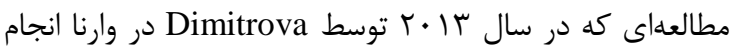
شد، در هيجيك از r T بيمار مبتلا به درماتيت سبورئيك (شامل 11 مرد و Iا زن)، سطح مطلوب ويتامين D مشاهده نكرديد.

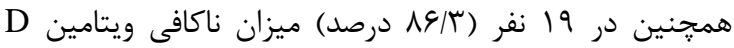

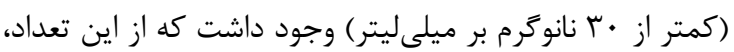

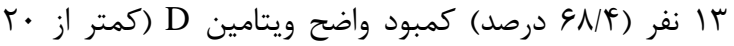

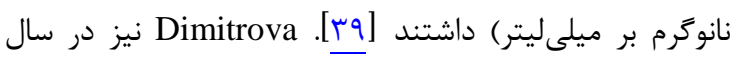

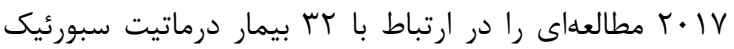

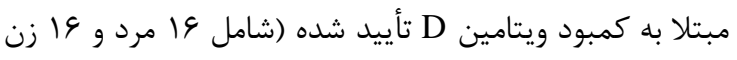

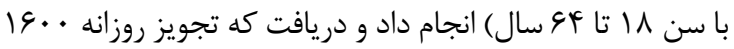
واحد كله كلسيفرول موجب كاهش عود درماتيت سبورئيك در

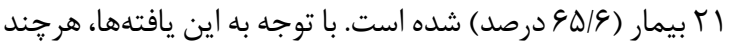

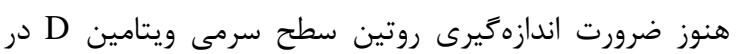
بيماران درماتيت سبورئيك تأييد نشده است؛ اما بهتر است ائ اين

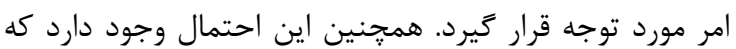

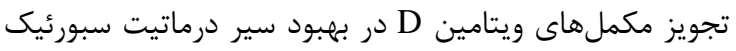

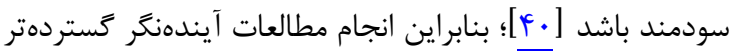
در اين زمينه لازم است. نتايج مطالعه حاضر نشان دادند كه تقريباً أو درصد از جمعيت مورد بررسى از سطح ناكافى ويتامين رنج مىبرند كه

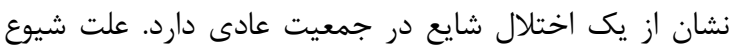

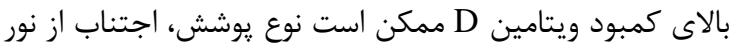
آفتاب، فعاليت بدنى كم و دريافت يايين ويتامين D در ور رزينم

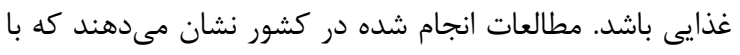
وجود شرايط جغرافيايى مناسب براى جذب ويتامين D، كمبود

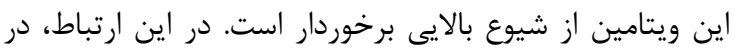

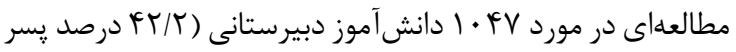

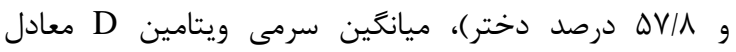

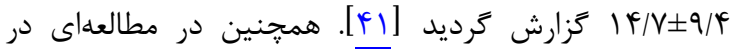

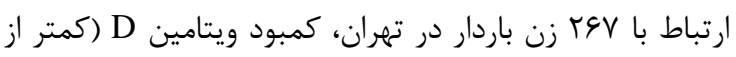

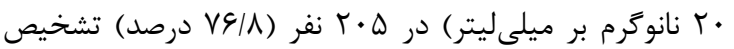

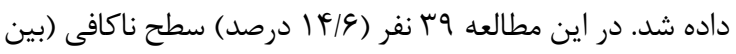

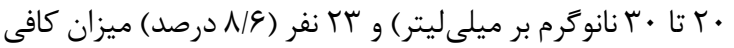

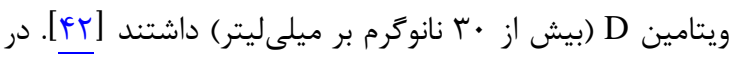

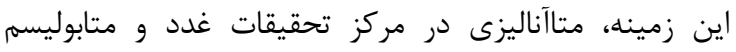

If [TV] د مطالعه روتردام، شيوع آن در بالغين و ميانسالان

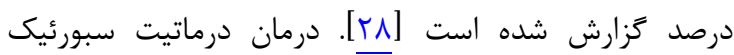

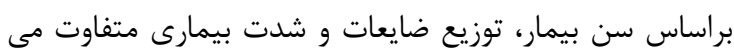

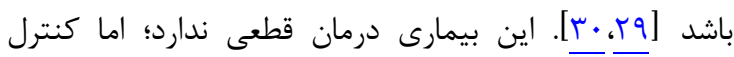

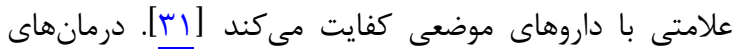
موضعى مختلف مانند كورتونها، ضد قارجها و آنتى ميكروبيال ها داريا

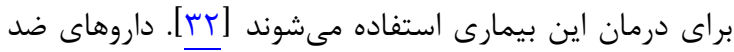

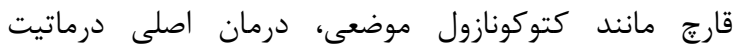
سبورئيك صورت و بدن است. داروهاى ضد التهابى مانند

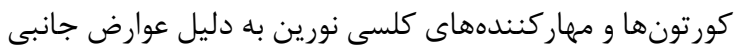
احتمالى، فقط به صورت كوتاه مدت استفاده مىشوند [بسارئ.

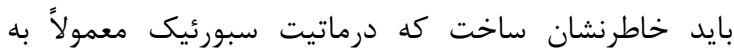

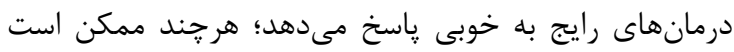

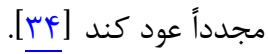

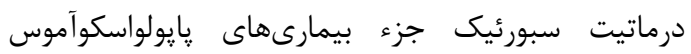

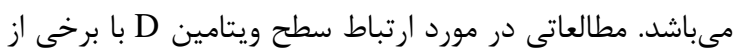

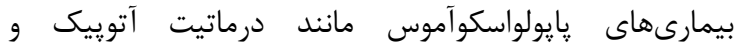

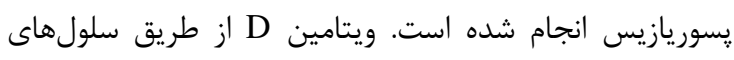

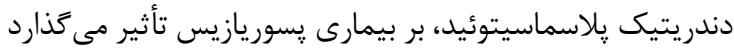

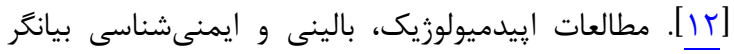

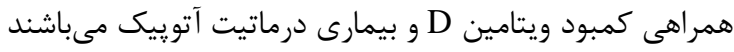

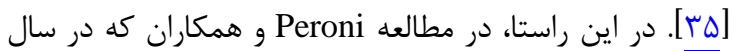

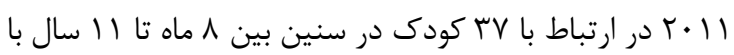

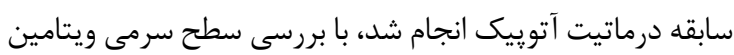

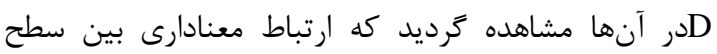

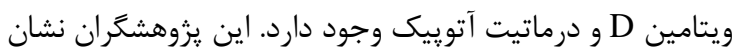
دادند كه كاهش سطح ويتامين D با شدت دات علائم بيمارى، ارتباطى معكوس دارد و نياز به انجام مطالعهاى در مورد استفاده

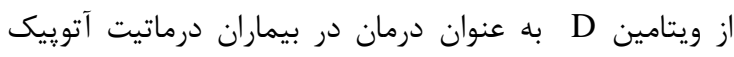

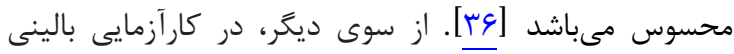

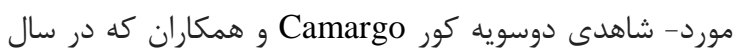

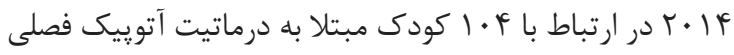

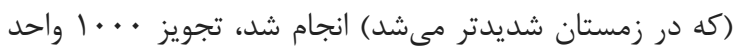

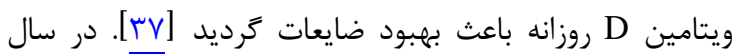

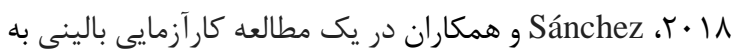

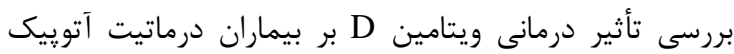

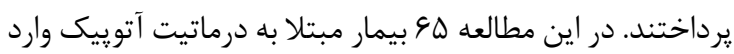

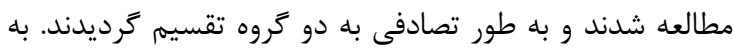

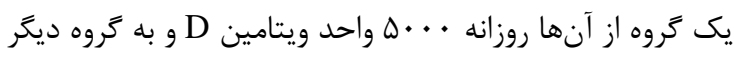

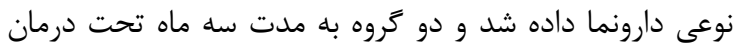

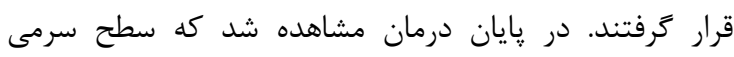

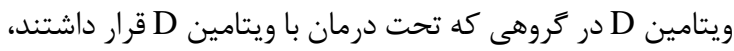
به طور معنادارى بالاتر از زروه كنترل بود (

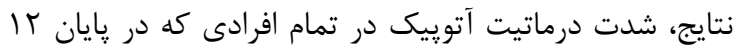


كه ممكن است با ياتوزنسيته اين بيمارى ارتباط داشته باشد.

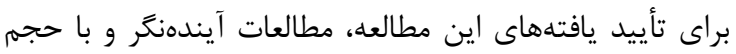

$$
\text { نمونه بيشتر ضرورت دارد. }
$$

\section{تشكر و قدر فانى}

اين مقاله بركرفته از پايان نامه دوره دكترى حرفهاى يزشكى

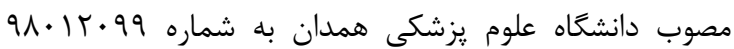
مىباشد. بدينوسيله از معاونت تحقيقات و فناورى دانشكاه و وانداه

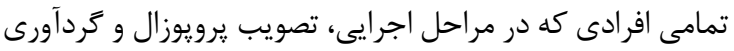

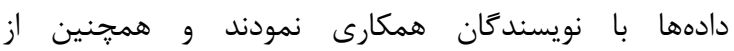
شركت كنندگان در مطالعه، صميمانه تشكر و قدردانى مى گر دد.

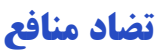
نتايج اين مطالعه با منافع نويسندكان در تعارض نمىباشد.

\section{ملاحظات اخلاقى}

مطالعه حاضر داراى تأييديه اخلاق در :زوهش با شناسه

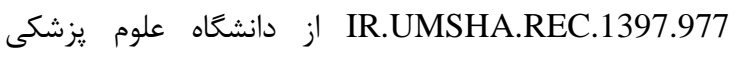

$$
\text { همدان مىباشد. }
$$

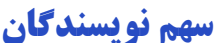

نويسنده اول (يزوهشكر اصلى): مسئول مكاتبات، طراحى نون

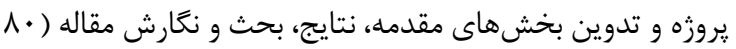

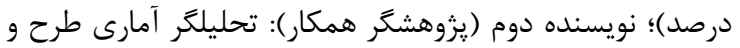

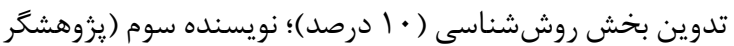

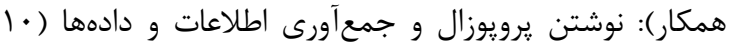

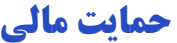

مطالعه حاضر از سوى معاونت تحقيقات و فناورى دانشخاه

$$
\text { علوم يزشكى همدان پشتيبانى مالى شده است. }
$$

\section{REFERENCES}

1. Sampaio AL, Mameri AC, Vargas TJ, Ramos-e-Silva M, Nunes AP, Carneiro SC. Seborrheic dermatitis. An Bras Dermatol. 2011;86(6):1061-71. PMID: 22281892 DOI: 10.1590/s0365-05962011000600002

2. Ijaz N, Fitzgerald D. Seborrhoeic dermatitis. Br J Hosp Med (Lond). 2017;78(6):C88-91. PMID: 28614013 DOI: 10.12968/hmed.2017.78.6.C 88

3. Quéreux G. Dermatitis seborreica. EMC Dermatol. 2019;53(1):1-9. DOI: 10.1016/S1761-2896(19)41715-9

4. Castillo DE, Gunczler I, França K, Keri J. Seborrheic dermatitis. Adv Integr Dermatol. 2019;71:552. DOI: 10.1002/9781119476009

5. Ooi ET, Tidman MJ. Improving the management of seborrhoeic dermatitis. Practitioner. 2014;258(1768):23-6. PMID: 24689165.

6. Prohic A, Kasumagic-Halilovic E. Identification of Malassezia species from immunocompetent and immunocompromised patients with seborrheic dermatitis. Eur Rev Med Pharmacol Sci. 2010;14(12):1019-23. PMID: 21375133
بيمارستان "نمازى" شيراز در ارتباط با \& F مطالعه با |rهA|

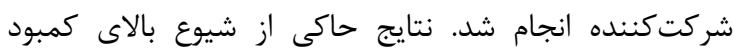

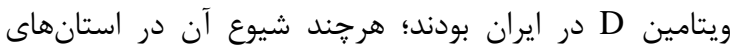

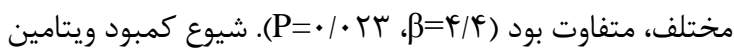

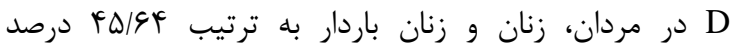
(CI=Yq/q CI=rr/Vr-qV/|q) (CI=F//VF

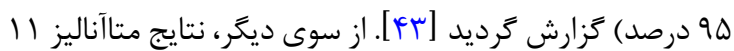

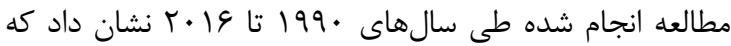

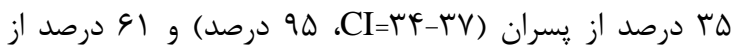

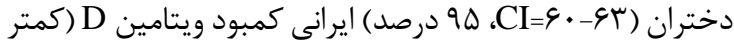

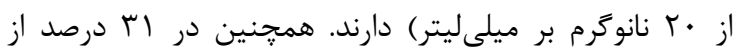

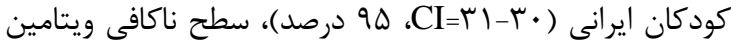

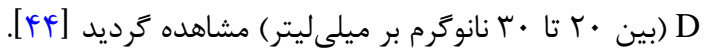
در مجموع، يافتههاى مطالعه حاضر نشان دادند كه بيماران

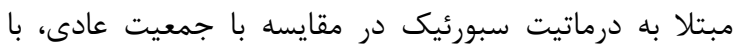

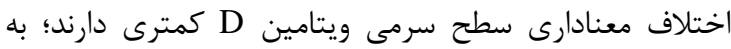
كونهاى كه سطح سرمى در اين بيماران در مقايسه با كروه كنترل

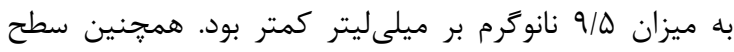

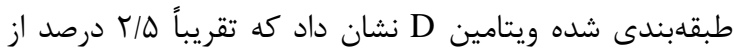
افراد مبتلا به بيمارى، سطح كافى ويتامين D (بيشتر و مساوى لندين

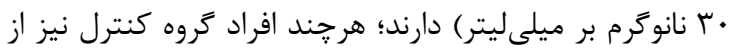

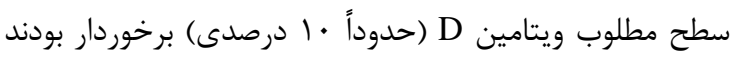
كه اين مهلم نشان مىدهد كه در جمعيت عادى، كمبود ويتامين يك مشكل اساسى و إيدمى مى باشد. در اين راستا، انجام

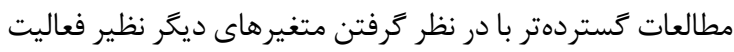
بدنى، رزيم غذايى، سطح سرمى كلسيم و پاراتورمون مى تواند

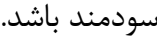

نتيجه كيرى

براساس يافتههاى اين مطالعه، بيماران درماتيت سبورئيك

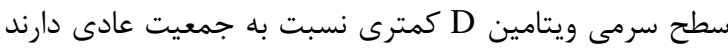

7. Zani MB, Soares RC, Arruda AC, de Arruda LH, Paulino LC. Ketoconazole does not decrease fungal amount in patients with seborrhoeic dermatitis. Br J Dermatol. 2016;175(2): 417-21. PMID: 26920094 DOI: 10.1111/bjd.14501

8. Dessinioti C, Katsambas A. Seborrheic dermatitis: etiology, risk factors, and treatments: facts and controversies. Clin Dermatol. 2013;31(4):343-51. PMID: 23806151 DOI: 10.1016/i.clindermatol.2013.01.001

9. Gupta A, Bluhm R, Cooper EA, Summerbell RC, Batra R. Seborrheic dermatitis. Dermatol Clin. 2003;21(3):401-12. PMID: 12956195 DOI: 10.1016/s0733-8635(03)00028-7

10. Sobhan M, Nazari F, Mohammadi Y. Correlation between seborrheic dermatitis and metabolic syndrome in patients referred to sina hospital of Hamadan. Avicenna J Clin Med. 2020;27(1):13-20. DOI: 10.29252/ajcm.27.1.13

11. Žmitek K, Hribar M, Hristov H, Pravst I. Efficiency of Vitamin D supplementation in healthy adults is associated with body mass index and baseline serum 25-hydroxyvitamin D level. Nutrients. 2020;12(5):1268. PMID: 32365732 DOI: 
10.3390/nu12051268

12. Karthaus N, van Spriel AB, Looman MWG, Chen S, Spilgies LM, Lieben L, et al. Vitamin D controls murine and human plasmacytoid dendritic cell function. J Invest Dermatol. 2014;134(5):1255-64. PMID: 24352045 DOI: 10.1038/ jid.2013.501

13. Kramer C, Seltmann H, Seifert M, Tilgen W, Zouboulis CC, Reichrath J. Characterization of the vitamin D endocrine system in human sebocytes in vitro. J Steroid Biochem Mol Biol. 2009;113(1-2):9-16. PMID: 19027855 DOI: 10.1016/j.jsbmb.2008.10.010

14. Teichert A, Bikle DD. Regulation of keratinocyte differentiation by vitamin $\mathrm{D}$ and Its relationship to squamous cell carcinoma. In: Glick A, Waes C, editors. Signaling pathways in squamous cancer. New York: Springer; 2011. DOI: 10.1007/978-1-4419-7203-3_14

15. Sahota O. Understanding vitamin D deficiency. Age Ageing. 2014;43(5):589-91. PMID: 25074537 DOI: $10.1093 /$ ageing/afu104

16. DeDea L. Understanding vitamin $\mathrm{D}$ formulations. JAAPA. 2013;26(10):10. PMID: 24201915 DOI: 10.1097/01.JAA. $0000435258.26357 .4 \mathrm{c}$

17. Schnatz PF, Manson JE. Vitamin D and cardiovascular disease: an appraisal of the evidence. Clin Chem. 2014;60(4):600-9. PMID: 24193116 DOI: 10.1373/clinchem.2013.211037

18. Bouillon R, Norman AW, Lips P. Vitamin D deficiency. $N$ Engl J Med. 2007;357(19):1980-1. PMID: 17989396 DOI: 10.1056/NEJMc072359

19. Holick MF. Vitamin D deficiency. $N$ Engl J Med. 2007; 357(3):266-81. PMID: 17634462 DOI: 10.1056/NEJMra070553

20. Reichrath J, Zouboulis CC, Vogt T, Holick MF. Targeting the vitamin D endocrine system (VDES) for the management of inflammatory and malignant skin diseases: An historical view and outlook. Rev Endocr Metab Disord. 2016;17(3):405-17. PMID: 27447175 DOI: 10.1007/s11154-016-9353-4

21. Bikle DD. Vitamin D regulated keratinocyte differentiation. J Cell Biochem. 2004;92(3):436-44. PMID: 15156556 DOI: $10.1002 / \mathrm{jcb} .20095$

22. Leyssens C, Verlinden L, Verstuyf A. The future of vitamin D analogs. Front Physiol. 2014;5:122. PMID: 24772087 DOI: $10.3389 /$ fphys.2014.00122

23. Umar M, Sastry K, S, Al Ali F, Al-Khulaifi M, Wang E, Chouchane A. Vitamin D and the pathophysiology of inflammatory skin diseases. Skin Pharmacol Physiol. 2018; 31(2):74-86. PMID: 29306952 DOI: 10.1159/000485132

24. Micali G, Lacarrubba F, Tedeschi A, Drischk T. A new proposed severity score for seborrheic dermatitis, seborrheic dermatitis area and severity index (SEDASI). $J$ Am Acad Dermatol. 2017;76(6):AB18. DOI: 10.1016/j.jaad.2017.04.088

25. Melamed ML, Michos ED, Post W, Astor B. 25hydroxyvitamin D levels and the risk of mortality in the general population. Arch Intern Med. 2008;168(15):1629-37. PMID: 18695076 DOI: 10.1001/archinte.168.15.1629

26. Sampogna F, Linder D, Piaserico S, Altomare G, Bortune M, Calzavara-Pinton P, et al. Quality of life assessment of patients with scalp dermatitis using the Italian version of the Scalpdex. Acta Derm Venereol. 2014;94(4):411-4. PMID: 24287710 DOI: $10.2340 / 00015555-1731$

27. Palamaras I, Kyriakis KP, Stavrianeas NG. Seborrheic dermatitis: lifetime detection rates. $J$ Eur Acad Dermatol Venereol. 2012;26(4):524-6. PMID: 21521374 DOI: 10.1111/j.1468-3083.2011.04079.x

28. Sanders MGH, Pardo LM, Franco OH, Ginger RS, Nijsten T. Prevalence and determinants of seborrhoeic dermatitis in a middle-aged and elderly population: the Rotterdam Study. $\mathrm{Br}$
J Dermatol. 2018;178(1):148-53. PMID: 28856679 DOI: 10.1111/bjd. 15908

29. Tucker D, Masood S. Seborrheic dermatitis. Treasure Island (FL): StatPearls Publishing; 2020. PMID: 31869171

30. Schmidt JA. Seborrheic dermatitis: a clinical practice snapshot. Nurse Pract. 2011;36(8):32-7. PMID: 21768832 DOI: $10.1097 / 01 . N P R .0000399717 .56736 .1 \mathrm{e}$

31. Menzinger S, Laffitte E. Seborrhoeic dermatitis: clinical manifestations and management. Rev Med Suisse. 2011; 7(289):752-4. PMID: 21568097

32. Cicek D, Kandi B, Bakar S, Turgut D. Pimecrolimus $1 \%$ cream, methylprednisolone aceponate $0.1 \%$ cream and metronidazole $0.75 \%$ gel in the treatment of seborrhoeic dermatitis: a randomized clinical study. J Dermatolog Treat. 2009;20(6):3449. PMID: 19954391 DOI: $10.3109 / 09546630802687349$

33. Clark GW, Pope SM, Jaboori KA. Diagnosis and treatment of seborrheic dermatitis. Am Fam Physician. 2015;91(3):18590. PMID: 25822272

34. Elgash M, Dlova N, Ogunleye T, Taylor SC. Seborrheic dermatitis in skin of color: clinical considerations. J Drugs Dermatol. 2019;18(1):24-7. PMID: 30681789

35. Borzutzky A, Camargo CA Jr. Role of vitamin D in the pathogenesis and treatment of atopic dermatitis. Expert Rev Clin Immunol. 2013;9(8):751-60. PMID: 23971753 DOI: 10.1586/1744666X.2013.816493

36. Peroni DG, Piacentini GL, Cametti E, Chinellato I, Boner AL. Correlation between serum 25-hydroxyvitamin $\mathrm{D}$ levels and severity of atopic dermatitis in children. $\mathrm{Br} \mathrm{J}$ Dermatol. 2011;164(5):1078-82. PMID: 21087229 DOI: 10.1111/j.13652133.2010.10147.x

37. Camargo CA Jr, Ganmaa D, Sidbury R, Erdenedelger K, Radnaakhand N, Khandsuren B. Randomized trial of vitamin D supplementation for winter-related atopic dermatitis in children. J Allergy Clin Immunol. 2014;134(4):831-5. PMID: 25282565 DOI: 10.1016/j.jaci.2014.08.002

38. Sánchez-Armendáriz K, García-Gil A, Romero CA, Contreras-Ruiz J, Karam-Orante M, Balcazar-Antonio D, et al. Oral vitamin D3 5000 IU/day as an adjuvant in the treatment of atopic dermatitis: a randomized control trial. Int J Dermatol. 2018;57(12):1516-20. PMID: 30238557 DOI: 10.1111/ijd.14220

39. Dimitrova J. Study of the level of 25-hydroxyvitamin D in patients with seborrheic dermatitis. Scripta Sci Med. 2013;45(1):75-8. DOI: 10.18638/arsa.2016.5.1.826

40. Dimitrova J. The effect of vitamin D supplementation on recurrences of seborrheic dermatitis. Int J Curr Adv Res. 2017;6(3):2446-8. DOI: 10.24327/ijcar.2017.2448.0025

41. Ebrahimi M, Khashayar P, Keshtkar A, Etemad K, Dini M, Mohammadi Z, et al. Prevalence of vitamin D deficiency among Iranian adolescents. J Pediatr Endocrinol Metab. 2014:27(78):595-602. PMID: 24854533 DOI: 10.1515/jpem-2013-0428

42. Sepandi M, Esmailzadeh S, Hosseini MS, Hashemi SR, Abbaszadeh S, Alimohamadi Y, et al. Prevalence of vitamin D deficiency among Iranian pregnant women. Nutr Diet Supplements. 2020;12:97-102. DOI: 10.2147/NDS.S261229

43. Tabrizi R, Moosazadeh M, Akbari M, Dabbaghmanesh MH, Mohamadkhani M, Asemi Z, et al. High Prevalence of vitamin $\mathrm{D}$ deficiency among Iranian population: a systematic review and meta-analysis. Iran J Med Sci. 2018;43(2):12539. PMID: 29749981

44. Jazayeri M, Moradi Y, Rasti A, Nakhjavani M, Kamali M, Baradaran HR. Prevalence of vitamin D deficiency in healthy Iranian children: a systematic review and meta-analysis. Med J Islam Repub Iran. 2018;32(1):480-5. PMID: 30643758 DOI: $10.14196 /$ mjiri.32.83 